\title{
Mapeamento de competências do psicólogo escolar
}

\author{
Dielem Cristina Oliveira dos Santos \\ Universidade Federal do Pará - Belém- PA- Brasil \\ Aline Beckmann de Castro Menezes \\ Universidade Federal do Pará - Belém - PA - Brasil \\ Aécio Borba \\ Universidade Federal do Pará - Belém - PA - Brasil \\ Camila Carvalho Ramos \\ Universidade Federal do Pará - Belém - PA - Brasil \\ Thiago Dias Costa \\ Universidade Federal do Pará - Belém - PA - Brasil
}

\section{Resumo}

Este artigo teve como objetivo realizar o mapeamento de competências do psicólogo escolar. Para tanto, foi realizado o levantamento e análise da produção bibliográfica e de documentos oficiais que discorrem sobre a sua atuação. Durante a análise, foram sugeridas e descritas competências avaliadas como necessárias à atuação deste profissional e após isto, foi contabilizada e organizada a frequência com que as competências apareceram nas diversas publicações analisadas. A partir da identificação de vários modelos de atuação, foram criadas categorias nas quais as competências correspondentes foram dispostas. A grande quantidade de competências identificadas e a necessidade da criação de categorias sugerem uma falta de clareza quanto à atuação do psicólogo escolar. Foi percebido, ainda, um aumento na quantidade de trabalhos elaborados na ultima década na tentativa de delimitar a atuação deste profissional.

Palavras-chave: Psicologia Escolar; atuação do psicólogo; competência.

\section{Mapping of competences of the school psychologist}

\begin{abstract}
This article aimed to perform the mapping of skills of the school psychologist. For that, a survey and analysis of bibliographical production and official documents were carried out to discuss its performance. During the analysis, competencies assessed as necessary for the performance of this professional were suggested and described and after this, the frequency with which the competencies appeared in the several analyzed publications was counted and organized. From the identification of several performance models, categories were created in which the corresponding competencies were established. The large number of competencies identified and the need to create categories suggest a lack of clarity regarding the performance of the school psychologist. It was also noticed an increase in the number of works elaborated in the last decade in the attempt to delimit the performance of this professional.
\end{abstract}

Keywords: School Psychology; psychologist performance; competence.

\section{Mapeo de competencias del psicólogo escolar}

\section{Resumen}

Este artículo tuvo como objetivo realizar el mapeo de competencias del psicólogo escolar. Para tanto, se realizó la recopilación y análisis de la producción bibliográfica y de documentos oficiales que discurren sobre su actuación. Durante el análisis, fueron sugeridas y descritas competencias evaluadas como necesarias a la actuación de este profesional y después de eso, se contabilizó y organizó la frecuencia con que las competencias aparecieron en las diversas publicaciones analizadas. A partir de la identificación de varios modelos de actuación, se crearon categorías en las cuales las competencias correspondientes fueron dispuestas. La gran cantidad de competencias identificadas y la necesidad de la creación de categorías sugieren una falta de claridad sobre la actuación del psicólogo escolar. Se percibió, aún, un aumento en la cantidad de estudios elaborados en la última década en la tentativa de delimitar la actuación de este profesional.

Palabras clave: Psicología Escolar; actuación del psicólogo, competencia. 


\section{Introdução}

A atuação do psicólogo escolar já é prevista desde a regulamentação da profissão, em 1962. Contudo só foi reconhecida como especialidade pelo Conselho Federal (CFP) de Psicologia em 2007. Nessa trajetória, muito mudou do que se esperava da atuação do psicólogo escolar e na forma como essa atuação se configurava no contexto educacional (Andrada, 2005; Martins, 2007).

Em um primeiro momento, a atuação do psicólogo escolar, como profissional responsável pela avaliação de alunos, identificação daqueles que estavam aptos à aprendizagem e ao "ajustamento" daqueles que destoavam da norma, foi instituída pelos próprios psicólogos escolares e educadores (para uma discussão histórica aprofundada ver, por exemplo, Guzzo, Mezzalira, Moreira, Tizzei, \& Silva Neto, 2010).

Tais práticas realizadas pelos psicólogos escolares passaram a ser criticadas a partir da década de 70 por serem consideradas inadequadas e insatisfatórias nas suas respostas ao ambiente escolar e, principalmente, devido ao viés clínico percebido (Guzzo \& cols., 2010).

Kupfer (2004) afirma que a tendência a defender o papel do psicólogo como agente de mudanças e propiciador de reflexões sobre a dinâmica do espaço escolar teria iniciado na década de 1990. Contudo, essa autora discute que a nova percepção do papel do psicólogo escolar tornou-se consensual e defendida pela maioria dos profissionais, mas na prática ainda prevalece no Brasil a conduta tradicional.

A indefinição na atuação do psicólogo escolar se deve a múltiplos fatores, dos quais podemos destacar: as expectativas da comunidade escolar sobre o papel do psicólogo (Martins, 2007), a formação recebida por estes profissionais em cursos de graduação (Cruces, 2006) e a ausência de competências profissionais descritas de forma clara, a partir de comportamentos observáveis (Santos, Kienen, Viecili, Botomé, \& Kubo, 2009).

Um conceito que pode ser considerado muito válido para a constituição do perfil profissional do psicólogo escolar é o de competência, que tem sido trabalhado no âmbito da gestão de organizações como a combinação de conhecimentos, habilidades e atitudes expressas pelo desempenho profissional (Brandão \& cols., 2008).

Desde 1990, várias iniciativas têm sido desenvolvidas na América do Norte e na Europa no sentido de promover a identificação, o treinamento e avaliação de competências profissionais na Psicologia. Em 2002, foi promovida uma conferência pela National Council of Schools and Programs of Professional Psychology (NCSPP) dos Estados Unidos, onde se reuniram diversos profissionais considerados especialistas em Educação e Psicologia, além de profissionais especialistas em trabalhar com o conceito de competências. Algumas conclusões do evento a serem destacadas foram, primeiramente, a importância de que os currículos fossem desenvolvidos a partir do conceito de competências e, segundo, que ao serem definidas competências, era possível identificar aspectos importantes da formação profissional que haviam sido historicamente negligenciados (Kaslow \& cols., 2004). Esse tipo de discussão também tem ocorrido em outros contextos internacionais, como a iniciativa desenvolvida pela British Psychology Society em 2014, englobando todos os países constituintes da Grã-Bretanha na definição de competências profissionais a serem desenvolvidas pelo psicólogo educacional em contexto de doutoramento (Dunsmuir \& Atkinson, 2015).

O presente estudo pretende, assim, contribuir com a discussão da identidade profissional do psicólogo escolar por meio de uma descrição de suas competências de acordo com a literatura da área. Para tal, propõe-se o mapeamento de competências desta atuação, identificando atividades condizentes com as exigências de situações individuais e coletivas no contexto de trabalho (Marinho-Araújo, 2007).

Para atingir tal objetivo, foi utilizado o referencial teórico proposto por Brandão (2012). Este estabelece que a identificação das competências deve ser operacionalizada em três pontos centrais: o primeiro é que os comportamentos necessários devem ser descritos como referenciais de desempenho, especificando comportamentos observáveis no trabalho; o segundo ponto busca as condições nas quais este comportamento deve ocorrer, aqui entendida como a descrição do contexto no qual aquele comportamento ocorre e/ou as metodologias necessárias e pertinentes à ocorrência do comportamento no ambiente de trabalho; e, por fim, a descrição de critérios, que indicam a descrição do que é considerado o padrão de qualidade satisfatório para o comportamento. A descrição de competência dessa forma contribui para descrições claras, que diminuem a possibilidade de interpretações equivocadas ou díspares sobre a atuação profissional. O mapeamento de competências pode ser, assim, uma estratégia relevante para a definição da atuação do psicólogo escolar, trazendo implicações para a formação de futuros profissionais e a avaliação de desempenho em instituições educacionais.

\section{Método}

\section{Procedimento}

Levantamento e análise da produção bibliográfica e de documentos oficiais

O levantamento e análise bibliográfica tiveram por objetivo identificar as competências profissionais necessárias à atuação do psicólogo escolar. Para tal, este procedimento foi dividido em dois momentos: 1) levantamento da produção bibliográfica e de documentos oficiais e 2) análise da produção bibliográfica e de documentos oficiais.

1.1 Levantamento da produção bibliográfica e de documentos oficiais.

O levantamento de artigos e teses foi realizado através da plataforma de periódicos CAPES e da Scientific Ele- 
tronic Library Online - SciELO - utilizando-se as seguintes palavras-chave: Psicologia escolar, Psicologia educacional, psicólogo escolar, psicólogo educacional, atuação do psicólogo escolar e atuação do psicólogo educacional. O levantamento seguiu três critérios: a) temporal: foram selecionados trabalhos publicados entre os anos de 2001 a 2014; b) área de conhecimento: foram escolhidos trabalhos referentes especificamente a Psicologia Escolar e Educacional e c) temático: foram incluídos apenas trabalhos que descrevem e/ ou definem a atuação profissional do psicólogo escolar.

Foi realizado, ainda, o levantamento de projetos político-pedagógicos (PPP) das universidades que tiveram avaliação 4 e 5 no Enade 2012 e de resoluções e leis que dispõem sobre a regulamentação da atuação profissional do psicólogo (Diário Oficial e Conselho Federal de Psicologia) e que instituem diretrizes curriculares nacionais para o curso de graduação de psicologia.

1.2 Análise da produção bibliográfica e de documentos oficiais.

Nesse segundo momento foi realizada a leitura das publicações e selecionados trechos nos quais era descrita a atuação do psicólogo escolar e/ou educacional. Esses trechos foram organizados em uma tabela e a partir deles foram sugeridas e descritas competências avaliadas como necessárias à atuação do profissional. Vale ressaltar que a descrição das competências foi realizada a partir dos critérios propostos por Brandão e Bahry (2005) nos quais a descrição de uma competência deve ser clara, de modo a evitar interpretações distintas sobre a que ela se refere. Desta forma, os trechos destacados eram compreendidos dentro do contexto utilizado pelo autor original e organizados segundo o tema geral que abordavam. O conjunto de trechos de diferentes documentos versando sobre um mesmo tema foi utilizado para a identificação de critérios e condições para cada. Os temas foram então convertidos em títulos que favorecessem a identificação da competência.
Após isto, a frequência com que as competências apareceram em cada documento oficial e produção científica foi contabilizada e organizada em uma tabela, na qual as competências sugeridas foram dispostas em ordem decrescente. A partir da identificação de diferentes modelos e tendências da atuação do psicólogo escolar, foram criadas categorias nas quais as competências correspondentes estão dispostas juntamente com sua frequência. Essas categorias foram criadas com base em trabalhos relacionados à atuação do psicólogo escolar.

\section{Resultados e Discussões}

Foram localizados e analisados, ao todo, 28 artigos, seis teses, cinco publicações do Conselho Federal de Psicologia e dois projetos político-pedagógicos. Quatro resoluções e leis foram consideradas pertinentes aos objetivos da pesquisa, sendo elas: a Lei $n^{\circ} 4.119,1962$ que dispõe sobre os cursos de formação em Psicologia e regulamenta a profissão de Psicólogo, a PL n 3.688, de 2000 que dispõe sobre a prestação de serviços de psicologia e de serviço social nas redes públicas de educação básica; a Resolução CFP n 02/01 que altera e regulamenta a Resolução CFP no 014/00 que institui o título profissional de especialista em psicologia e o respectivo registro nos Conselhos Regionais e a Resolução n 8, de 2004, que Institui as Diretrizes Curriculares Nacionais para os cursos de graduação em Psicologia.

Após a análise da produção bibliográfica dos documentos oficiais foram identificadas 44 competências referentes à atuação do psicólogo escolar. A descrição das competências foi embasada na interpretação das leituras realizadas e elaborada a partir da proposta de Brandão e Bahry (2005) na qual a descrição de uma competência deve apresentar um verbo e um objeto de ação, podendo ser complementada por um critério que indique um padrão de qualidade satisfatório e uma condição na qual se espera que o comportamento ocorra, conforme exemplo no Quadro 1.

Quadro 1 - Exemplo de construção da competência utilizando Verbo + Objeto da ação, Critério e Condição.

\begin{tabular}{|c|}
\hline Trecho Selecionado \\
\hline $\begin{array}{l}\text { "Apresentaram alguns temas específicos solicitados pela instituição, como } \\
\text { abuso sexual infantil e relação família-creche" (Vieira, Hansen, \& Vieira 2009). }\end{array}$ \\
\hline Competência Sugerida \\
\hline Apresentar Trabalhos \\
\hline Descrição da competência \\
\hline $\begin{array}{l}\text { Apresentar trabalhos (Verbo + Objeto da ação) de forma clara e objetiva } \\
\text { (Critério) utilizando recursos audiovisuais ou outros tipos de materiais de apoio de } \\
\text { acordo com as características do público-alvo (Condição). }\end{array}$ \\
\hline
\end{tabular}


Modalidades de atuação e categorias de
competências

Durante a leitura das publicações foram identificadas diversas formas de atuação do psicólogo escolar, o que pode sugerir tanto uma grande variabilidade nas demandas ao psicólogo escolar, como uma falta de clareza a respeito da prática profissional. Foram criadas, sistematizadas, a partir da literatura, modalidades de atuação que refletissem as características e procedimentos utilizados pelo psicólogo no ambiente escolar. Esses modelos de atuação foram cria- dos com base nos trabalhos de Marinho-Araújo e Almeida (2005) e Souza (2009): o Modelo de Atuação Clínica, nos quais a atuação tem como foco o aluno e estão ligadas principalmente na detecção de problemas de aprendizagem, avaliação e atendimento psicológico; o Modelo de Atuação Institucional, no qual a atuação profissional é estendida aos diversos membros da comunidade escolar e está ligado a uma atuação preventiva. A partir deste modelo foram criadas ainda duas outras categorias, sendo a primeira relacionada ao Modelo de Atuação Institucional tendo como público-alvo unicamente o aluno e a segunda desvinculada de um modelo

Tabela 1. Quantidade de ocorrências de Competências do Modelo de Atuação Institucional por tipo de documento.

\begin{tabular}{|c|c|c|c|c|c|c|}
\hline Competência & $\mathbf{N}^{\circ}$ & Artigos & Teses & CFP & Normas ${ }^{1}$ & PPP \\
\hline Atuação Interdisciplinar & 43 & 20 & 8 & 8 & 5 & 2 \\
\hline Promover Espaços de Diálogo & 31 & 21 & 6 & 4 & 0 & 0 \\
\hline Assessoria e Orientação & 27 & 18 & 5 & 3 & 1 & 0 \\
\hline Análise Institucional & 26 & 17 & 2 & 3 & 2 & 2 \\
\hline Atuação Junto ao Docente & 24 & 16 & 5 & 3 & 0 & 0 \\
\hline Elaborar Pesquisas e Estudos & 24 & 12 & 3 & 3 & 4 & 2 \\
\hline Formação Continuada de Professores & 23 & 17 & 5 & 1 & 0 & 0 \\
\hline Atuação Junto à Família & 23 & 17 & 3 & 3 & 0 & 0 \\
\hline Elaborar Projeto Político-Pedagógico & 20 & 9 & 4 & 3 & 2 & 2 \\
\hline Gestão de Projetos e Programas & 20 & 10 & 3 & 3 & 2 & 2 \\
\hline Mediação & 20 & 11 & 3 & 4 & 2 & 0 \\
\hline Análise Contextual & 16 & 8 & 4 & 3 & 1 & 0 \\
\hline Atuação Preventiva & 14 & 11 & 2 & 0 & 1 & 0 \\
\hline Avaliação & 14 & 6 & 3 & 3 & 0 & 2 \\
\hline Desenvolvimento de Agentes Educacionais & 13 & 8 & 2 & 1 & 2 & 0 \\
\hline Atuação Junto aos Funcionários & 13 & 10 & 2 & 1 & 0 & 0 \\
\hline Planejamento & 11 & 5 & 2 & 2 & 2 & 0 \\
\hline Promover Eventos e Oficinas & 11 & 8 & 2 & 1 & 0 & 0 \\
\hline Estabelecer Parcerias & 10 & 1 & 4 & 4 & 1 & 0 \\
\hline Políticas Públicas Educacionais & 10 & 2 & 3 & 2 & 1 & 2 \\
\hline Atuação Junto à Comunidade & 9 & 6 & 2 & 1 & 0 & 0 \\
\hline Despatologização do Fracasso Escolar & 9 & 5 & 2 & 2 & 0 & 0 \\
\hline Análise do Clima Educacional & 8 & 3 & 0 & 2 & 1 & 2 \\
\hline Auxílio à Gestão Escolar & 7 & 5 & 1 & 1 & 0 & 0 \\
\hline Recrutamento e Seleção & 6 & 4 & 0 & 1 & 1 & 0 \\
\hline Apresentar Trabalhos & 6 & 3 & 0 & 1 & 2 & 0 \\
\hline Atenção à Saúde & 4 & 3 & 0 & 0 & 1 & 0 \\
\hline Promover Esclarecimentos & 4 & 2 & 0 & 2 & 0 & 0 \\
\hline
\end{tabular}

${ }^{1}$ Resoluções e Leis governamentais acerca da atuação do Psicólogo Escolar. 
específico, sendo aqui denominada de "Competências Pessoais" do psicólogo escolar, por se referir a competências necessárias ao psicólogo ante a si mesmo para o aperfeiçoamento da sua prática profissional. Desta forma, totalizaram quatro categorias, sendo uma relacionada à atuação clínica, uma geral e uma à institucional.

Nos anexos I, II, III e IV é possível visualizar as competências e a descrição das competências sugeridas.

\section{Modelo de Atuação Institucional}

Conforme a Tabela 1 demonstra, o Modelo de Atuação Institucional apresentou 28 das 44 competências, número relacionado às várias demandas exigidas do psicólogo escolar, que se relaciona com diversos atores da comunidade escolar - diretores, professores, pais, demais funcionários da escola e profissionais internos ou externos envolvidos nas atividades acadêmicas. Deve-se ainda destacar o grande número de estudos contemporâneos sobre esse modelo, o que também contribui para o aumento do número de competências descritas. A competência com maior frequência foi a de Atuação Interdisciplinar (43 ocorrências), sendo observada em todos os tipos de documentos analisados. Em seguida, destacou-se a competência "Promover Espaços de Diálogo" (31 ocorrências) - atuação muito abordada em artigos e teses sobre a área e prevista pelo CFP.
Duas competências ainda pouco discutidas são as de Promover Esclarecimentos e Atenção à Saúde, ambas com quatro ocorrências, sendo a primeira prevista pelo CFP e a segunda estabelecida na Resolução nº 8 de 2004.

\section{Modelo de Atuação Institucional Junto ao Aluno}

Nesta categoria, criada a partir do Modelo de Atuação Institucional, tendo como público-alvo unicamente o aluno, a competência com maior frequência foi a de Acompanhamento do Processo Ensino-Aprendizagem (16 ocorrências). Esta atuação junto ao aluno tem sido amplamente discutida em artigos e teses a respeito da área e é prevista pelo CFP, conforme Tabela 2.

\section{Competências Pessoais}

A competência com maior frequência nesta categoria foi Atuação Crítica (19 ocorrências), o que reflete os discursos contemporâneos referentes à atuação do psicólogo escolar. Tais estudos têm defendido uma postura crítica desse profissional frente aos modos de produção da queixa e do fracasso escolar (como Andrada, 2005, Guzzo \& cols., 2010 e Marinho-Araújo, 2007). Essa postura também tem sido citada pelo CFP em trabalhos referentes à área, conforme Tabela 3.

Tabela 2. Quantidade de ocorrências de Competências Institucionais- Atuação Junto ao Aluno por tipo de documento

\begin{tabular}{|c|c|c|c|c|c|c|}
\hline Competência & $\mathbf{N}^{\circ}$ & Artigos & Teses & CFP & Normas $^{1}$ & PPP \\
\hline $\begin{array}{c}\text { Acompanhamento do Processo Ensino- } \\
\text { Aprendizagem }\end{array}$ & 16 & 12 & 1 & 3 & 0 & 0 \\
\hline Educação Especial & 13 & 4 & 3 & 3 & 1 & 2 \\
\hline Promover Espaços de Diálogo com Alunos & 12 & 6 & 3 & 3 & 0 & 0 \\
\hline Orientação Psicopedagógica & 10 & 7 & 2 & 1 & 0 & 0 \\
\hline Orientação Profissional & 8 & 4 & 1 & 1 & 2 & 0 \\
\hline Orientação Individualizada & 6 & 4 & 0 & 1 & 1 & 0 \\
\hline Suporte Emocional & 6 & 5 & 0 & 1 & 0 & 0 \\
\hline Encaminhamento & 5 & 4 & 0 & 1 & 0 & 0 \\
\hline
\end{tabular}

Tabela 3. Quantidade de ocorrências de Competências Pessoais por tipo de documento.

\begin{tabular}{ccccccc}
\hline Competência & $\mathbf{N}^{\mathbf{0}}$ & Artigos & Teses & CFP & Normas $^{1}$ & PPP \\
\hline Atuação Crítica & 19 & 13 & 4 & 2 & 0 & 0 \\
\hline Relacionamento Interpessoal & 14 & 10 & 2 & 1 & 1 & 0 \\
\hline Atualização Teórica e Prática & 11 & 5 & 2 & 3 & 1 & 0 \\
\hline Iniciativa e Proatividade & 8 & 4 & 2 & 2 & 0 & 0 \\
\hline Autogerenciamento & 4 & 2 & 1 & 1 & 0 & 0 \\
\hline
\end{tabular}


Tabela 4. Quantidade de ocorrências de Competências Clínicas por tipo de documento.

\begin{tabular}{ccccccc}
\hline Competência & $\mathbf{N}^{\mathbf{0}}$ & Artigos & Teses & CFP & Normas $^{1}$ & PPP $^{2}$ \\
\hline Avaliação Psicológica & 22 & 12 & 1 & 1 & 6 & 2 \\
\hline Intervenção Psicopedagógica & 9 & 3 & 0 & 2 & 2 & 2 \\
\hline Atendimento Clínico & 5 & 4 & 0 & 0 & 1 & 0 \\
\hline
\end{tabular}

\section{Modelo de Atuação Clínica}

A competência mais presente no modelo de atuação clínica foi a de Avaliação Psicológica (22 ocorrências): essa competência foi identificada em todos os tipos de publicações, conforme pode ser visto na Tabela 4. A competência com menor frequência foi a de Atendimento Clínico (cinco ocorrências) identificada na Resolução n 8, 2004 e em artigos nos quais os autores relatavam a prática de psicólogos no ambiente escolar, o que pode revelar a diferença entre o discurso teórico e a prática profissional.

O pequeno número de competências identificadas nesse modelo de atuação pode indicar a baixa variabilidade dos procedimentos que podem ser utilizados pelo psicólogo ao optar por essa atuação. O Modelo de Atuação Clínica implica, assim, especificamente em competências derivadas da prática psicoterápica, em especial de diagnóstico e intervenção.

Vale ressaltar que apesar do Modelo de Atuação Clínica ter como alvo principal o aluno, a variabilidade de competências identificadas é bem menor em comparação às competências identificadas na categoria de Atuação Institucional Junto ao Aluno.

\section{Considerações Finais}

Das 44 competências identificadas, 28 são concernentes ao Modelo de Atuação Institucional, oito são relacionadas à Atuação Institucional Junto ao Aluno, cinco concernentes a Competências Pessoais e três são relacionadas ao Modelo de Atuação Clínica.

A quantidade de competências que fazem referência ao Modelo de Atuação Institucional (que totalizam 41, caso sejam contabilizadas as três categorias relativas a este modelo), pode refletir não apenas o grande número de trabalhos em defesa desse modelo de atuação, mas também a variabilidade de ações e procedimentos que o psicólogo pode adotar no ambiente escolar.

Diferentemente do Modelo Institucional, o reduzido número de competências no Modelo de Atuação Clínica pode refletir a crítica e o repúdio feito a esse modelo pelos autores contemporâneos devido ao questionamento de sua eficácia no ambiente escolar e mesmo de sua pertinência, já que pode assumir uma função prejudicial ante o fracasso escolar (ver as críticas de Andrada, 2005 e Kupfer, 2004 por exemplo).

As tabelas apresentadas mostram ainda como as competências encontradas em trabalhos científicos e publicações do CFP se distinguem em frequência das leis e resoluções que dispõem sobre a atuação do psicólogo. Isto suscita o questionamento acerca da atualidade, ou mesmo pertinência, das atuações do psicólogo escolar tal qual previsto em documentos legais. Esse dado merece uma análise posterior mais detalhada, mas pode-se hipotetizar que reflita as expectativas existentes na comunidade acerca do que seria o trabalho do psicólogo escolar (Guzzo \& cols., 2010).

Outro fator que vale destacar refere-se às competências identificadas nos PPPs, em que estas não parecem refletir a realidade da atuação do psicólogo escolar - podendo indicar uma relação com a legislação vigente, tal qual apresentado anteriormente. Vale ressaltar que as competências encontradas nesses documentos estão apenas baseadas nas Diretrizes Curriculares Nacionais para os cursos de graduação em Psicologia e não contêm competências específicas que deveriam ser desenvolvidas pelo graduando de psicologia para cada área de atuação do psicólogo, conforme indica a produção da área. Para aprimorar a formação de futuros profissionais, a discussão destas competências específicas nos âmbitos dos cursos de graduação faz-se relevante e urgente.

Uma melhor análise sobre o significado e a pertinência das competências elaboradas no presente trabalho poderá ser desenvolvida a partir de estudos posteriores com entrevistas a profissionais atuantes na área. Desta forma, poderá ser estruturado um referencial sobre a prática do psicólogo escolar que auxilie a formação tanto de novos profissionais quanto a formação continuada de profissionais já atuantes na área.

\section{Referências}

Andrada, E. G. (2005). Novos paradigmas na prática do psicólogo escolar. Psicologia: Reflexão e Crítica, 18 (2), 196-199.

Brandão, H. P. \& Bahry, C. P. (2005). Gestão por competências: métodos e técnicas para mapeamento de competências. Revista do Serviço Público, 56 (2), 179- 194. 
Brandão, H. P. (2012). Mapeamento de competências - métodos, técnicas e aplicações em Gestão de Pessoas. São Paulo: Atlas.

Brandão, H. P., Zimmer, M. V., Pereira, C. G., Marques, F., Costa, H. V., Carbone, P. P., \& Almada, V. F. (2008). Gestão de Desempenho por Competências: integrando a gestão por competências, o balanced score card e a avaliação360 graus. Revista de Administração Pública, 42 (5), 875-898.

Cruces, A. V. V. (2006). Egressos de cursos de psicologia: Preferências, especializações, oportunidades de trabalho e atuação na área educacional. Tese de Doutorado, Instituto de Psicologia, Universidade de São Paulo, São Paulo, SP.

Dunsmuir, S. \& Atkinson, C. (2015). Using Delphi Methodology to Define Curriculum Content for Educational Psychology Training. Conferência apresentada no $37^{\text {th }}$ International School Psychology Association (ISPA) São Paulo: Universidade Presbiteriana Mackenzie em São Paulo.

Guzzo, R. S. L., Mezzalira, A. S. C, Moreira, A. P. G., Tizzei, R. P., \& Silva Neto, W. M. F. (2010). Psicologia e Educação no Brasil: Uma Visão da História e Possibilidades nessa Relação. Psicologia: Teoria e Pesquisa, 26 (Especial), 131-141.

Kaslow, N. J., Borden, K. A., Collins Jr., F. L., Forrest, L., Illfelder-Kaye, J., Nelson, P. D., Rallo, J. S., Vasquez, M. J. T., \& Willmuth, M. E. (2004). Competencies Conference: Future Directions in Education and Credentialing in Professional Psychology. Journal of Clinical Psychology, 60 (7), 699-712.

Kupfer, M. C. M. (2004). O que toca à/a Psicologia Escolar. In: A. M. Machado \& M. P. R. Souza (Orgs.), Psicologia escolar: em busca de novos rumos (pp. 55-65). São Paulo: Casa do Psicólogo.

Lei $n^{\circ} 4.119$ de 27 de agosto de1962 (1962). Dispõe sobre os cursos de formação em Psicologia e regulamenta a profissão de Psicólogo. Diário Oficial da União. Brasília, DF.

Marinho-Araújo, C. M. (2007). A psicologia escolar nas diretrizes curriculares: espaços criados, desafios instalados. Em H. R. Campos (Orgs.), Formação em psicologia escolar: realidades e perspectivas (pp. 17-48). Campinas: Alínea.

Marinho-Araújo, C. M. \& Almeida, S. F. C. (2005). Psicologia escolar: construção e consolidação da identidade profissional. Campinas, SP: Alínea.

Martins, J. B. (2007). A atuação do psicólogo escolar: Multirreferencialidade, implicação e escuta clínica. Psicologia em Estudo, 8(2), 39-45.

Projeto de Lei $n^{\circ} 3.688$, de 2000 (2000). Dispõe sobre a prestação de serviços de psicologia e de serviço social nas redes públicas de educação básica.

Resolução do Conselho Federal de Psicologia no 02/01, de 10 de março de 2001 (2001, 10 de março). Altera e regulamenta a Resolução CFP no 014/00 que institui o título profissional de especialista em psicologia e o respectivo registro nos Conselhos Regionais. Conselho Federal de Psicologia. Brasília, DF.

Resolução $n^{\circ} 8$, de 18 de maio de 2004 (2004, 18 de maio). Institui as Diretrizes Curriculares Nacionais para os cursos de graduação em Psicologia. Diário Oficial da União, Brasília, DF.

Santos, G. C. V., Kienen, N., Viecili, J., Botomé, S. P., \& Kubo, O. M. (2009). "Habilidades" e "Competências" a Desenvolver na Capacitação de Psicólogos: Uma Contribuição da Análise do Comportamento para o Exame das Diretrizes Curriculares. Interação em Psicologia, 13 (1), 131-145.

Souza, M. P. R. (2009). Psicologia Escolar e Educacional em busca de novas perspectivas. Psicologia Escolar e Educacional, 13 (1). Recuperado: 24 jan. 2011. Disponível: http://www.scielo.br/pdf/ pee/v13n1/v13n1a21.pdf.

\section{Anexos}

\section{Anexo I - Competência do Modelo de Atuação Institucional}

Competência e descrição sugerida:

- Atuação Interdisciplinar: Atuar de forma cooperativa com a equipe multiprofissional, considerando o projeto político-pedagógico, auxiliando na melhoria do processo de ensino-aprendizagem.

- Promover Espaços de Diálogo: Desenvolver espaços que promovam o diálogo entre os membros da comunidade escolar visando favorecer a problematização de questões presentes no contexto escolar e o desenvolvimento de propostas para solução destas.

- Análise Institucional: Analisar as relações entre os múltiplos segmentos do sistema educacional, considerando suas características particulares, para auxiliar no atendimento das necessidades institucionais com relação ao processo educacional.

- Atuação Junto ao Docente: Avaliar, orientar e acompanhar o professor em sua relação com o discente, contribuindo para a promoção da aprendizagem e desenvolvimento do aluno.

- Elaborar Pesquisas e Estudos: Desenvolver pesquisas e estudos utilizando diferentes métodos de investigação científica, visando o atendimento das necessidades institucionais e o desenvolvimento do conhecimento científico.

- Formação Continuada de Professores: Promo- 
ver discussões que auxiliem a formação continuada de professores com foco no desenvolvimento de competências que favoreçam a atuação junto aos alunos, bem como o planejamento e avaliação dos processos de ensino-aprendizagem.

- Atuação Junto à Família: Promover o atendimento e acolhimento à família possibilitando a coleta de informações sobre o aluno e o desenvolvimento de propostas para solução de questões presentes no contexto escolar.

- Elaborar Projeto Político-Pedagógico: Colaborar com a equipe escolar na construção do projeto político-pedagógico, de acordo com as políticas de educação e a realidade escolar.

- Gestão de Projetos e Programas: Elaborar, implantar acompanhar e reformular projetos e programas, juntamente com a equipe escolar, para o aperfeiçoamento e promoção de novos procedimentos institucionais, de acordo com as características da população-alvo.

- Assessoria e Orientação: Expedir recomendações aos agentes educacionais na elaboração e implementação de programas de apoio administrativo e educacional.

- Mediação: Atuar como mediador nas relações sociais e institucionais, favorecendo a articulação entre os membros da comunidade escolar e auxiliando na resolução de conflitos e obtenção de acordos.

- Análise Contextual: Analisar o contexto da realidade educacional e as possibilidades de atuação profissional, planejando ações e procedimentos que garantam a consecução dos objetivos institucionais.

- Atuação Preventiva: Propor estratégias de promoção e bem estar aos membros da comunidade escolar, de forma preventiva, sobre potenciais circunstâncias e demandas no contexto escolar.

- Avaliação: Colaborar com a equipe escolar na avaliação de projetos educacionais, estratégias de aprendizagem e estrutura curricular para o auxilio da melhoria dos processos educacionais.

- Desenvolvimento de Agentes Educacionais: Auxiliar na construção de programas que orientem os agentes educacionais na adaptação ao trabalho e/ou ações de desenvolvimento, treinamento e capacitação, utilizando metodologias pertinentes, de acordo com os objetivos da instituição.

- Atuação Junto aos Funcionários: Promover espaços de diálogo com funcionários buscando o atendimento de suas demandas e consequentemente a garantia de sua participação na instituição escolar.
- Planejamento: Definir objetivos, ações e resultados alinhados aos interesses e estratégias da instituição.

- Promover Eventos e Oficinas: Planejar, executar e acompanhar eventos e oficinas que auxiliem o desenvolvimento dos membros da comunidade escolar e atendam os objetivos institucionais.

- Estabelecer Parcerias: Estabelecer parcerias e diálogo com a comunidade e redes sociais de apoio para o planejamento de ações de saúde e cultura que forneçam cuidado integral ao aluno.

- Políticas Públicas Educacionais: Contribuir com a elaboração e/ou implementação de políticas públicas educacionais adequadas ao ambiente escolar e que colaborem para a promoção do desenvolvimento educacional.

- Atuação Junto à Comunidade: Implementar, participar e/ou apresentar propostas de atividades que ampliem a participação e a integração da comunidade com a escola.

- Despatologização do Fracasso Escolar: Acompanhar alunos e orientar profissionais de modo a lidar com dificuldades de aprendizagem rompendo com a cultura de patologização e a medicalização dos alunos.

- Análise do Clima Educacional: Analisar e intervir no clima educacional buscando oportunidades de melhorias no ambiente escolar, especialmente na relação entre alunos, professores e gestores.

- Auxílio à Gestão Escolar: Auxiliar na gestão escolar contribuindo para a construção e/ou manutenção de uma gestão democrática que viabilize a participação de toda comunidade escolar na promoção do desenvolvimento institucional.

- Recrutamento e Seleção: Selecionar e recrutar profissionais de acordo com o perfil da vaga a ser preenchida, utilizando técnicas de seleção de pessoal e oferecendo feedback.

- Apresentar Trabalhos: Apresentar trabalhos de forma clara e objetiva utilizando estratégias de comunicação criativas e diversificadas de acordo com as características do público-alvo.

- Atenção à Saúde: Desenvolver ações de prevenção, promoção, proteção e reabilitação da saúde psicológica e psicossocial, tanto em nível individual quanto coletivo, bem como a realizar seus serviços dentro de padrões de qualidade e dos princípios da ética/bioética.

- Promover Esclarecimentos: Promover esclarecimentos aos profissionais da Educação e aos demais membros da comunidade escolar sobre o papel e atuação do psicólogo escolar/educacional. 
Anexo II - Modelo de Atuação Institucional Junto ao Aluno

Competência e descrição sugerida:

- Acompanhamento do Processo Ensino-Aprendizagem: Acompanhar o desempenho escolar do aluno, visando auxiliar na melhoria do seu processo de ensino-aprendizagem.

- Educação Especial: Propor programas e ações adequados às especificidades de cada aluno com necessidades especiais e à legislação vigente, que auxiliem a sua inclusão e o seu processo de ensino-aprendizagem.

- Promover Espaços de Diálogo com Alunos: Promover espaços de diálogo com alunos possibilitando o estabelecimento de vínculo e confiança além de criar possibilidades de escuta e oportunidades de dar voz aos mesmos dentro da instituição escolar.

- Orientação Psicopedagógica: Auxiliar na prevenção e identificação de dificuldades de aprendizagem, considerando as condições bio-psico-sócio-culturais do aluno.

- Orientação Profissional: Auxiliar na escolha de carreira e construção de planos profissionais de alunos a partir da realização de espaços promotores de reflexão e autoconhecimento.

- Orientação Individualizada: Realizar orientação e/ou aconselhamento psicológico, auxiliando na melhoria do processo educacional do aluno.

- Suporte Emocional: Atender a demandas psicológicas emergenciais do aluno visando promover a escuta e o acolhimento do mesmo.

- Encaminhamento: Realizar encaminhamento de alunos para profissionais especializados fora da instituição escolar em casos excepcionais, nos quais sua complexidade e especificidade assim o demandem.

\section{Anexo III - Competências Pessoais}

Competência e descrição sugerida

- Atuação Crítica: Analisar os fenômenos educativos de forma crítica, promovendo a problematização das múltiplas determinações do fracasso escolar e dos modos de produção da queixa escolar.

- Relacionamento Interpessoal: Estabelecer, manter e melhorar interações com/entre os membros da comunidade escolar de forma assertiva e respeitosa, garantindo a boa conservação do clima institucional.

- Atualização Teórica e Prática: Atualizar-se continuamente quanto à teoria e a prática, tanto em relação aos conhecimentos da psicologia quanto a outros conhecimentos técnico-científicos que sejam pertinentes à prática profissional dentro do ambiente escolar.

- Iniciativa e Proatividade: Atuar de forma preventiva, de acordo com o projeto pedagógico da instituição e das políticas públicas de educação, sem a necessidade de orientação prévia.

- Autogerenciamento: Buscar feedback sobre o seu próprio desempenho identificando possibilidades de melhoria contínua de sua atuação.

\section{Anexo IV - Modelo de Atuação Clínica \\ Competências e descrição sugeridas:}

- Atendimento Clínico: Realizar intervenção psicológica às demandas do aluno auxiliando-o em suas dificuldades emocionais, comportamentais e/ou cognitivas.

- Avaliação Psicológica: Realizar avaliação psicológica individualmente ou em grupo, utilizando técnicas aprovadas pelo Conselho Federal de Psicologia, com a finalidade de explicar fenômenos psicológicos e subsidiar processos decisórios no âmbito escolar.

- Intervenção Psicopedagógica: Intervir frente a problemas de aprendizagem, aplicando conhecimentos e estratégias individualmente e/ou em grupo que auxiliem no desenvolvimento sócio-afetivo e cognitivo. 


\section{Sobre os autores}

Dielen Cristina Oliveira dos Santos (dielem.cristina@gmail.com)

Acadêmica do curso de Psicologia na Universidade Federal do Pará.

Aline Beckmann de Castro Menezes (alinebcm@gmail.com)

Doutorado em Psicologia (Teoria e Pesquisa do Comportamento) pela Universidade Federal do Pará. Professor Adjunto da Universidade Federal do Pará.

Aécio Borba (aecioborba@gestcomufpa.org)

Doutorado em Psicologia (Teoria e Pesquisa do Comportamento) pela Universidade Federal do Pará. Professor Adjunto da Universidade Federal do Pará.

Camila Carvalho Ramos (camilakrvalho@gmail.com)

Doutorado em Psicologia (Teoria e Pesquisa do Comportamento) pela Universidade Federal do Pará. Pós-Doutoranda da Universidade Federal do Pará.

Thiago Dias Costa (thiagodiascosta@gmail.com)

Doutorado em Psicologia (Teoria e Pesquisa do Comportamento) pela Universidade Federal do Pará. Professor Adjunto IV da Universidade Federal do Pará.

ERRATA Doi:http://dx.doi.org/10.1590/2175-3539201803003 -- No artigo: SANTOS, Dielen Cristina Oliveira dos et al. Mapeamento de competências do psicólogo escolar. Psicol. Esc. Educ. \{online\}. 2017, vol.21, n.2 \{cited 2018-09-27\}, pp.225-234. Available from: <http://www.scielo.br/scielo.php?script=sci_arttext\&pid=S1413-85572017000200225\&lng=en\&nrm=iso>. ISSN 2175-3539. http://dx.doi.org/10.1590/2175-3539201702121109. -- Onde se lê: Dielen Cristina Oliveira dos Santos, Leia-se: Dielem Cristina Oliveira dos Santos 